\title{
Clonal T Cell Responses in Tumor Infiltrating Lymphocytes from both Regressive and Progressive Regions of Primary Human Malignant Melanoma
}

\author{
Per thor Straten, ${ }^{\star}$ Jürgen C. Becker, ${ }^{\ddagger}$ Tina Seremet, ${ }^{\star}$ Eva Bettina Bröcker, ${ }^{\ddagger}$ and Jesper Zeuthen ${ }^{\star}$ \\ $*$ Department of Tumor Cell Biology, Division of Cancer Biology, Danish Cancer Society, DK-2100 Copenhagen, Denmark; and ${ }^{\ddagger}$ School \\ of Medicine, Department of Dermatology, D-8700 Würtzburg, Germany
}

\begin{abstract}
The $\mathrm{T}$ cell receptor (TCR) BV variable (V) gene repertoire of tumor infiltrating lymphocytes (TIL) found in progressive and regressive regions of the same primary human melanomas were characterized by reverse transcription coupled polymerase chain reaction (RT-PCR). After surgery, the tumors were divided into different parts which were judged as regressive or progressive regions by visual inspection. Subsequently this diagnosis was confirmed by histology. From a total of four primary melanomas analyzed, 2 were shown to be HLA-A2 ${ }^{+}$. Only relatively few BV-gene families were expressed at significant levels in each of the samples. Comparison of the $\mathrm{BV}$-expression in regressive versus progressive regions of the same tumor revealed major differences in all cases examined. Direct sequencing of RT-PCR products indicated that highly expressed BV-gene families were of clonal origin in both the regressive and progressive regions. Together, these data strongly suggest the occurrence of clonal $T$ cell responses in both regressive and progressive areas of the same primary tumor. The differences in expression of certain BV-genes may correlate with the functional activity of certain populations of tumor-infiltrating $\mathrm{T}$ cells. (J. Clin. Invest. 1996. 97:279-284.) Key words: TCRBVexpression - sequence - HLA-A2 - immunosurveillance • melanoma
\end{abstract}

\section{Introduction}

There is consensus that melanoma cells are antigenic since they express tumor-associated antigens that are recognized by syngeneic T cells. Furthermore, cellular components which should be able to cause rejection of the tumor, i.e., T lymphocytes and macrophages are infiltrating both primary and metastatic tumors. Nevertheless, the prognosis of melanoma which can not be cured by surgical resection is one of the most unfavorable in medicine. The coexistence of tumor specific immunity with a progressing tumor remains a major paradox of tumor immunology. This enigma is most evident in partially regressing melanoma, where efficient eradication of tumor cells occurs in close vicinity to uncontrolled tumor growth.

\footnotetext{
Address correspondence to Professor Jesper Zeuthen, Danish Cancer Society, Strandboulevarden 49, DK-2100 Copenhagen, Denmark. Phone: 45-35 2573 00, FAX: 45-31 3820 44; E-mail: JZ@kbbio.kb.inst.dk

Received for publication 26 February 1996 and accepted in revised form 25 April 1996.
}

J. Clin. Invest.

(C) The American Society for Clinical Investigation, Inc.

0021-9738/96/07/0279/06 \$2.00

Volume 98, Number 2, July 1996, 279-284
Spontaneous regression of malignant melanoma has been defined by Everson and Cole (1) as the partial or complete disappearance of a malignant tumor in the absence of all treatment. Such spontaneous regressions of primary cutaneous melanoma are not uncommon and are clinically manifested by a decrease in the amount of pigmentation, variation in color, division of the original lesion into multiple smaller lesions, and scarring.

Tumor infiltrating lymphocytes (TIL) consist mostly of $\mathrm{T}$ cells expressing an $\alpha / \beta \mathrm{T}$ cell receptor (TCR). The usage of TCR variable (V) repertoires of tumor-infiltrating lymphocytes (TIL) ${ }^{1}$ in primary human melanomas has recently been characterized indicating the presence of expanded $\mathrm{T}$ cells in the tumor (2-4). However, all studies thus far have analyzed the TCR V-region repertoire in the total tumor sample. The occurrence of spontaneous regression of primary melanoma is correlated with a high degree of lymphocyte infiltration (5). Therefore, it is possible that clonal $\mathrm{T}$ cell responses may originate exclusively from the regressive parts of the tumor.

To test this notion, we have analyzed the $\mathrm{T}$ cell repertoires in regressive versus progressive regions of different primary melanomas by RT-PCR. The expression of the 24 different BV-families was analyzed. Only very few BV-gene families were found to be expressed with major differences in regressive versus progressive regions of the same tumor. The highly expressed $\mathrm{BV}$-gene families were found to be clonal in both regressive and progressive parts of the same tumor, suggesting a clonal $\mathrm{T}$ cell response to occur in each part of the primary tumors.

\section{Methods}

Tumor samples. Fresh primary melanoma lesions were received as biopsy material immediately after surgery performed at the Department of Dermatology, School of Medicine, Würtzburg. Four patients were included in this study. The tumors were examined for Clark level, type, localization, and thickness (Table I). The tumors were separated into progressive and regressive regions by visual inspection which was subsequently validated by histological analysis (Fig. 1).

Isolation of RNA and synthesis of $c D N A$. RNA was extracted by a modification of the method described by Chomczynski and Sacchi $(6,7)$. cDNA synthesis was performed according to the manufacturers' protocol using M-MLV reverse transcriptase (Life Technologies Inc., Gaithersburg, MD). Incubations were performed at $42^{\circ} \mathrm{C}$ for 30 $\min , 99^{\circ} \mathrm{C}$ for $5 \mathrm{~min}$, and then terminated on ice.

To analyze equal amounts of TCR cDNA from each sample, different cDNA dilutions were amplified by PCR with primers for the constant region of the B-chain (Primers CB-5' and CB-3' 1 . PCR amplification; 20 cycles, reamplification; 35 cycles). The amounts of cDNA to be used for the BV-analyses were determined on the basis of the intensity of these PCR-products observed after agarose gel electrophoresis.

1. Abbreviations used in this paper: $\mathrm{B}$, beta-chain; TCR, T cell receptor; TIL, tumor-infiltrating lymphocytes; $\mathrm{V}$, variable. 
Table I. HLA-A2 Expression and Histopathological Characteristics of the Tumor Samples

\begin{tabular}{lccccc}
\hline Tumor & HLA-A2 & Localization & Type* & Thickness & $\begin{array}{c}\text { Clark } \\
\text { level }\end{array}$ \\
\hline 1 & - & Trunk & NMM & $1.5 \mathrm{~mm}$ & V \\
2 & + & Arm & SSM & $1.4 \mathrm{~mm}$ & IV \\
3 & - & Leg & SSM & $1.8 \mathrm{~mm}$ & IV \\
4 & + & Trunk & SSM & $1.9 \mathrm{~mm}$ & IV
\end{tabular}

* SSM, superficial spreading melanoma; $N M$, nodular melanoma

TCRBV PCR. PCR amplification of TCRBV 1-24, was performed with 24 different $5^{\prime}$-primers specific for BV families 1-24 together with a 3'-primer CB4 or CB-seq2, matching the constant region of the TCR B-chain. The specificity of the primer sets have been carefully designed in order to prime all members of each family, and at the same time avoiding cross-reactivity between the different families. ${ }^{2}$ Since the amount of cDNA was limited, each analysis was performed initially with 20 cycles using CB4 as 3'-primer. Aliquots from this first amplification were diluted $1 / 100$ and $5 \mu l$ of this sample were amplified by further 35 cycles of PCR using a nested $3^{\prime}$-primer (CBseq2). Reactions were carried out as described ${ }^{2}$ with the exception that in the reamplification reaction, the primer concentrations were raised from 1,25 to $5 \mathrm{pmol}$ and the dNTP concentrations were raised from 10 to $50 \mu \mathrm{M}$.

Cross contamination was avoided by use of plugged pipette tips (Multi Technology Inc. Salt Lake City, Utah) and separate rooms for pre- and post-PCR handling. Negative controls were samples without cDNA. All amplifications were performed in a Hybaid Omnigene Thermal Cycler (Hybaid, Teddington, Middlesex, UK) using standard microtubes (Multi Technology Inc., Salt Lake City, Utah).

For analysis, $15-\mu l$ aliquots of PCR products were subjected to electrophoresis in 3\% NuSieve 3:1 agarose gel (FMC BioProducts) for $3 \mathrm{~h}$ at $100 \mathrm{~V}$.

HLA-A2 PCR. Analysis of HLA-A2 ${ }^{+}$mRNA expression was performed by RT-PCR. The parameters were as described above with the exception that the "touch down" was carried out from $70^{\circ} \mathrm{C}$ to $62^{\circ} \mathrm{C}$. Two different HLA-A2- samples were analyzed as negative controls. Primers used were 5'-GGGACGGGGAGACACGGAAA$3^{\prime}$ (sense) and (5'-AGCGGATCCAGTCATATGCGTTTTGGGGGC-3' (antisense) taken from published HLA-A2 cDNA nucleotide sequence (8). The underlined sequence corresponds to an added BamHI site. The resulting PCR product consists of $390 \mathrm{bp}$.

Southern blots. After electrophoresis, PCR products were transferred to nylon membranes and hybridized as previously described. ${ }^{2}$ 1/1 mixtures of $\gamma$ - $\left[{ }^{33} \mathrm{P}\right]$ end-labeled oligonucleotides, BHYB1 (5'-AACACCTTGTTCAGGTC-3') and BHYB2 (5'-AACACGTTTTTCAGGTC-3'), which match CB1 and CB2, respectively, were used as probes. After washing, the radioactive probes were visualized using a Molecular Dynamics Storage Phosphor Phosphorimager (9).

Sequence analysis. Highly expressed BV-regions were sequenced in order to investigate the clonality of their expression. After re-amplification, the PCR products were extracted from agarose gel, precipitated with ethanol and resuspended in $10 \mu \mathrm{l} 1 \times$ PCR buffer (Perkin Elmer Cetus, Emeryville, CA). Sequenase version 2.0 (USB Corporation, Cleveland, $\mathrm{OH}$ ) was used following the manufacturers' suggestions. However, in order to sequence directly, we used a $\gamma-\left[{ }^{33} \mathrm{P}\right]$ dATP end-labeled primer (Cßseq2) and denaturation was carried out by boiling for $5 \mathrm{~min}$ in a total volume of $12 \mu \mathrm{l}$. The gels were analyzed with a Molecular Dynamics Phosphorimager.

2. thor Straten, P., P. Ralfkiær, J. Hendriks, T. Seremet, G. Lange Vejlsgaard, and J. Zeuthen, manuscript submitted for publication.
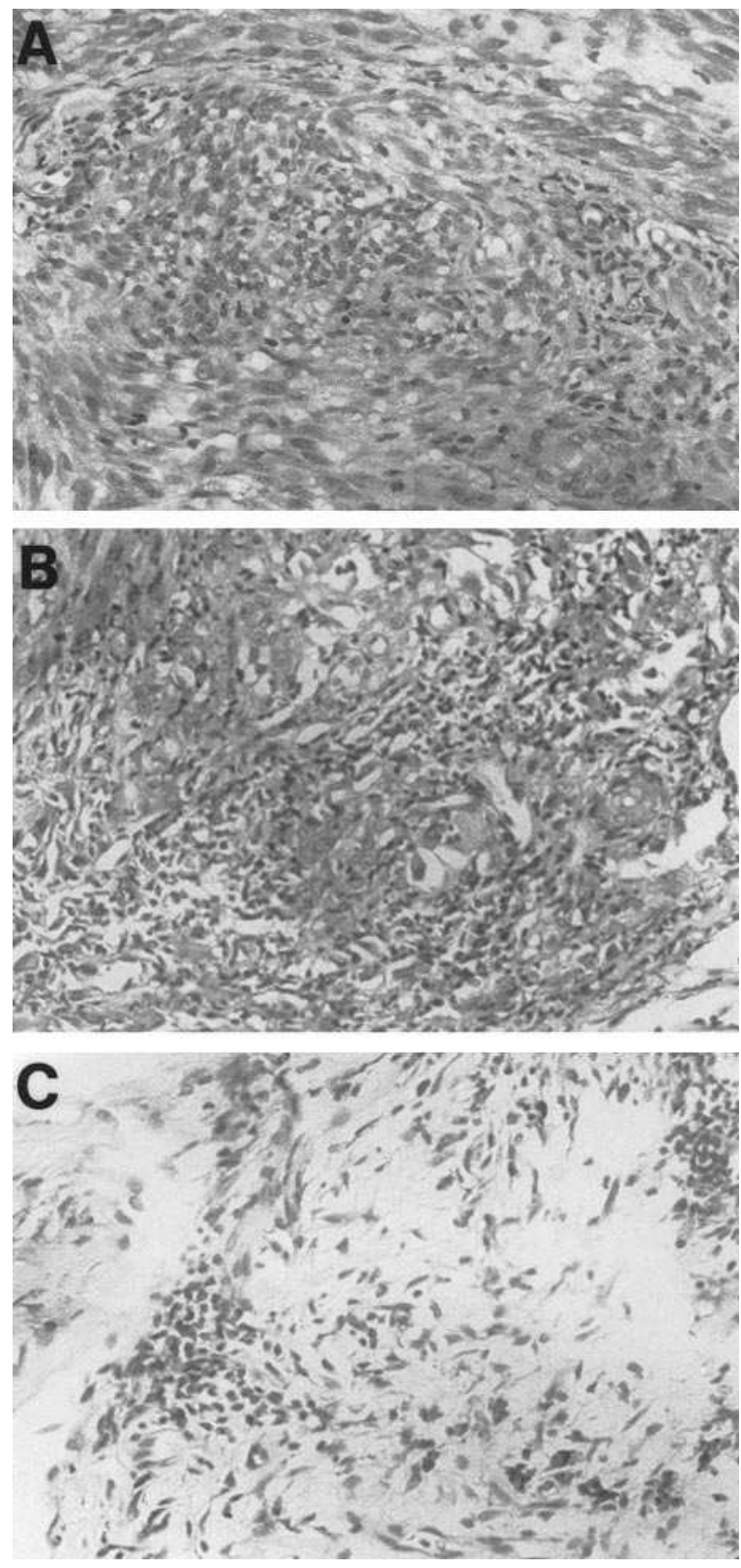

Figure 1. (A) primary malignant melanoma with no signs of regression and a scattered infiltrate of lymphocytes. $(B)$ intermediate phase of regression showing a brisk inflammatory infiltrate with lymphocytes and some melanin laden macrophages. $(C)$ late phase of regression with scarring showing dermal edema, fibrosis and some focal accumulation of lymphocytes and macrophages (hematoxylin-eosin, $\times 200)$.

\section{Results}

$T C R B V$ repertoire in regressive and progressive parts of primary melanoma. RT-PCR was used together with a panel of highly specific V-region primers (VB1-VB24) to compare the TCRBV repertoire of TIL infiltrating regressive and progressive parts of four primary melanoma tumors. Each amplified RT-PCR product was obtained with the expected size as a single band in all cases.

A limited number of BV-regions were expressed at significant levels $(\leq 5 \%)$ in each sample. The number of BV-regions 
Table II. TCRBV Expression and Clonality in the Tumor Samples

\begin{tabular}{ll}
\hline Tumor 1 progressive & $\mathrm{BV} 4,{ }^{*} \mathrm{BV} 5,{ }^{*} \mathrm{BV} 8,{ }^{\ddagger} \mathrm{BV} 13 *$ \\
Tumor 1 regressive & $\mathrm{BV} 3,{ }^{*} \mathrm{BV} 5, \mathrm{BV} 13,{ }^{*} \mathrm{BV} 18$ \\
Tumor 2 progressive & $\mathrm{BV} 4,{ }^{*} \mathrm{BV} 12, \mathrm{BV} 14$ \\
Tumor 2 regressive & $\mathrm{BV} 2,{ }^{*} \mathrm{BV} 4, \mathrm{BV} 12, \mathrm{BV} 20^{*}$ \\
Tumor 3 progressive & $\mathrm{BV} 13,{ }^{*} \mathrm{BV} 14,{ }^{*} \mathrm{BV} 20$ \\
Tumor 3 regressive & $\mathrm{BV} 6,{ }^{*} \mathrm{BV} 13, \mathrm{BV} 21, \mathrm{BV} 24^{*}$ \\
Tumor 4 progressive & $\mathrm{BV} 3, \mathrm{BV} 5, \mathrm{BV} 14,{ }^{*} \mathrm{BV} 15,{ }^{\ddagger} \mathrm{BV} 17^{\ddagger}$ \\
Tumor 4 regressive & $\mathrm{BV} 1,{ }^{*} \mathrm{BV} 3,{ }^{\ddagger} \mathrm{BV} 5, \mathrm{BV} 7, \mathrm{BV} 13,{ }^{\ddagger} \mathrm{BV} 15$
\end{tabular}

TCRBV-regions expressed in progressive and regressive parts of the tumor samples. *Regions shown by sequence analysis to be of clonal origin. ${ }^{*}$ Regions not sequenced.

expressed at significant levels in each tumor ranged from 7 to 11. In general, the regions BV3, BV4, BV5, BV13, BV14, and $\mathrm{BV} 20$ were expressed in more than one tumor, whereas the regions BV1, BV2, BV6, BV7, BV8, BV12, BV15, BV17, BV18, BV21, and BV24 were expressed in one tumor only (Table II). No two samples had the same or similar pattern of BV gene expression. For example, both patients 1 and 4 show expression of BV3, BV5 and BV13. However, regions BV1, BV4, BV7, BV14, BV15, and BV17 are expressed exclusively in one of the tumors. Some BV regions were not found to be expressed in any of the tumors. This goes for BV9, BV10, BV11, BV16, BV19, BV22, and BV23. Comparing the expression of specific TCRBV in the different areas of the tumor in all cases analyzed showed major differences. Examples of this phenomenon is the expression of BV18 which is highly expressed in sample 1 regressive (reg.) and absent in sample 1 progressive (prog.); BV1 in tumor 4 reg. but absent in tumor 4 prog. and BV14 present in tumor 4 prog. but not in tumor 4 reg. (Fig. 2), and BV20, which is highly expressed in tumor 2 reg. but absent in tumor 2 prog. However, in all tumors analyzed one or a few regions were expressed in both parts of the tumor (Table II).

HLA-A2 RT-PCR. The expression of HLA-A2 was examined with specific primers for HLA-A2 and RT-PCR under highly stringent conditions. The results showed correctly sized
PCR products derived from the amplification of cDNA from tumor 2 and 4 (Table I).

Sequence analysis. Several BV-regions were sequenced in order to investigate whether any of these regions were of clonal origin. From a total of 28 PCR products sequenced, 14 of these revealed distinct CDR3 regions, all showing the expected BV-region sequence (Table III). Readable CDR3 sequences were found in both regressive and progressive parts of the same tumors. In the sample $1 \mathrm{reg} . / 1$ prog. both the regressive and the progressive regions of this tumor showed expression of BV13. The sequence analysis in both cases showed a readable CDR3 region; however the sequences were different. In tumor 4, both parts of the tumor showed a readable CDR3 region (BV14 and BV1, respectively). However, the BV5 region expressed in both parts of this tumor showed a non-readable CDR3 region. Table III depicts the nucleotide sequence as well as the deduced amino acid sequence from those sequences showing a readable CDR3.

\section{Discussion}

$\mathrm{T}$ cell clones raised from TILs are capable of eliciting specific cytotoxicity against autologous melanoma cells (10). We (2, 11) and others $(4,12)$ have previously analyzed $T$ cell responses in human primary malignant melanoma and found in situ expansions of TIL population. These results indicate that in vivo HLA-restricted cytotoxic T cell responses may occur at the tumor site. Since malignant melanoma nevertheless is one of the most malignant of tumors, it has been proposed that some tumor cells must escape this T cell response (13). Malignant melanoma in many cases show clear signs of regression in some parts whereas other parts of the same tumor show progression (14). So far, all studies on TCR usage in primary melanoma were based on RNA extracted from the total tumor mass $(2,4,12,15)$. In fact, one of the studies used tumor specimens showing clear signs of tumor regression (12). Therefore it is possible that progressive samples or progressive parts of the tumors, would not give rise to specific HLA-restricted T cell responses, as two known tumor escape mechanism is loss of HLA or antigen (16-18). If this is the case, it should not be possible to detect a clonal $\mathrm{T}$ cell response in these parts of the tumors.

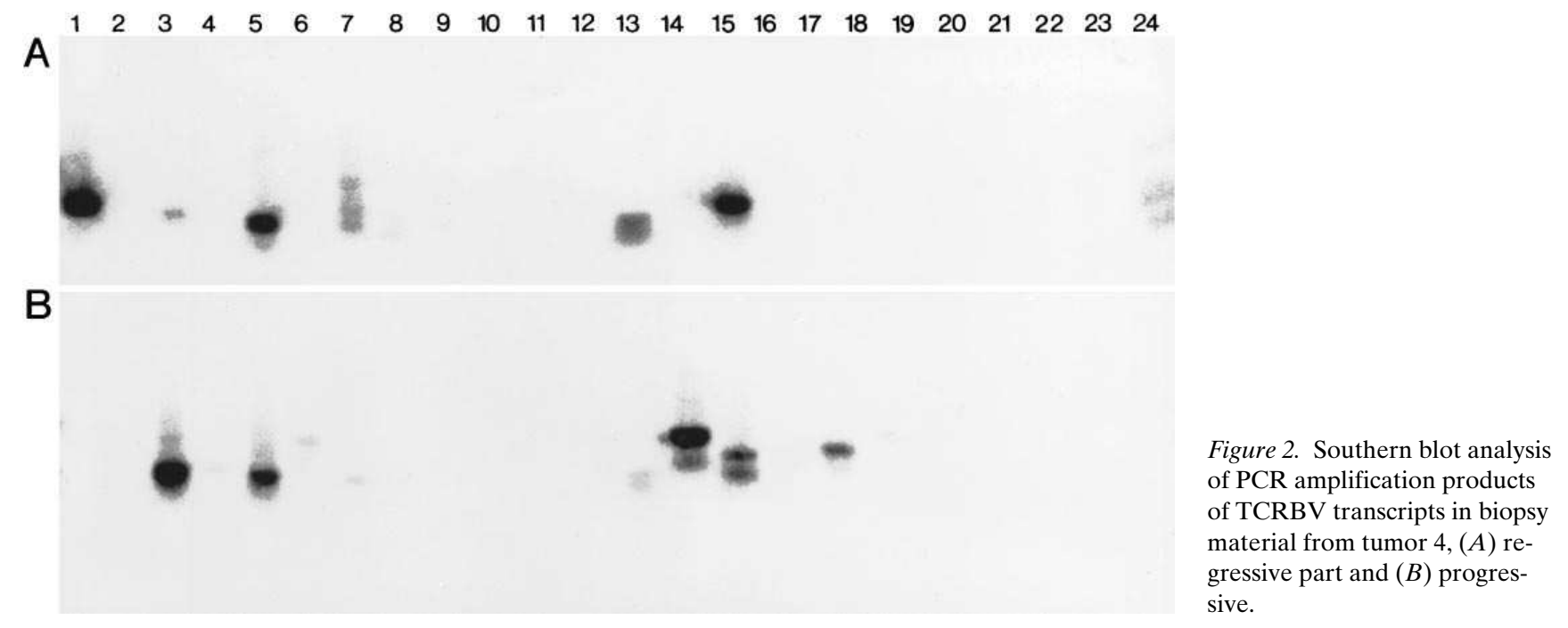


prog. BV4J2S3 TAT CTC TGC AGC GTT GGG TTA CTA GGG ACA CAG TCC ACA GAT ACG CAG TAT TTT GGC CCA GGC ACC CGG CT

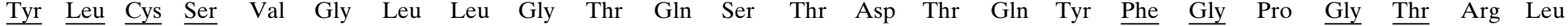

BV5J2s5 TAT CTT TGC GCC AGC ACC TGG GGC GCG GGG ATA GAG ACC CAA ACC TTC GGG CCA GGC ACG CGG CTC CTG GTG CT

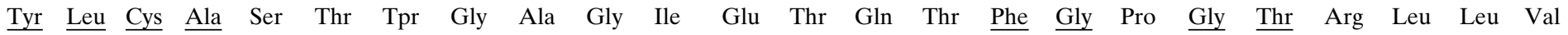

BV13J2S2 TAC TTC TGT GCC AGC AGG GCC GGG GGC CCG AAC ACC GGG GAT CTG TTT TTT GGA GAA GGC TCT A $\underline{\text { Tyr }} \underline{\text { Phe }} \underline{\text { Cys }} \underline{\text { Ala }}$ Ser Arg Ala Gly Gly Pro Asn Thr Gly Asp Leu Phe Gly Glu Gly $\underline{\text { Ser }}$ Arg

Tumor 1

reg. BV3J1S1 TAC CTC TGT GCC AGC AGT TTA CCG GAC GAG AGG AAC ACT GAA GCT TTC TTT GGA CAA GGC ACC AGA CT $\underline{\text { Tyr }} \underline{\text { Leu }} \underline{\text { Cys }} \underline{\text { Ala }}$ Ser Leu Pro Asp Glu Arg Asn $\quad$ Thr Glu Ala Phe $\underline{\text { Phe }} \underline{\text { Gly }}$ Gln Gly $\underline{\text { Thr }}$ Arg Leu Thr Val

BV13J1S2 TAC TTC TGT GCC AGC AGC AAT ATT TAC CCC CCG GGA CAG GGG GAT GGC TAC ACC TTC GGT TCG GGG ACC AGG TTA ACC GT

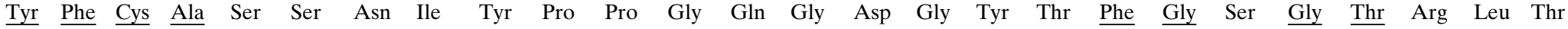

Tumor 2

prog. BV4J1S2 TAT CTC TGC AGC GTT GTG CTG GGC TAT GGC TAC ACC TTC GGT TCG GGG ACC AGG $\underline{\text { Tyr }} \underline{\text { Leu }} \underline{\text { Cys }} \underline{\text { Ser }}$ Val Val Leu Gly Tyr Gly Tyr Thr $\underline{\text { Phe }} \underline{\text { Gly }}$ Ser $\underline{\text { Gly }} \underline{\text { Thr }}$ Ser

Tumor 2

reg. BV2J2S5 TTC TAC ATC TGC AGT GGG AAA CTA GAG ACC CAG TAC TTC GGG CCA GGC ACG CGG CTC CTG GTG Phe Tyr Ile Cys Ser Gly Lys Leu Glu Thr Lsn Tyr Phe Gly Pro Gly $\quad$ Thr Arg Leu Leu Val

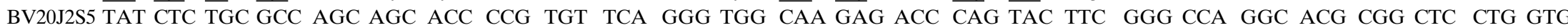
Tyr Leu Cys Ala Ser Ser Thr Pro Cys $\quad$ Ser Gly Trp Gln Glu Thr Gln Tyr Phe Gly Pro Gly Thr Arg Leu Leu Val

Tumor 3

prog. BV13J2S7 TAC TTC TGT GCC AAC CGT AGG GCC CTA CTC CAC GAG CAG TAC TTC GGG CCG GGC ACC AGG CTC Tyr Phe Cys Ala Asn Arg Arg Ala Leu Leu His Glu Gln Tyr Phe Gly Pro Gly Thr Arg Leu BV14J155 TAC TTC TGT GCC AGC AGT TCG ACA GGG AAT CAG CCC CAG CAT TTT GGT GAT GGG ACT CGA GTC TCC TAT CC

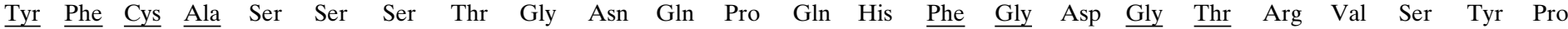

Tumor 3

reg. BV6J1S5 TAT CTC CGT GCC AGC AGC TTA ACG CAG CGG GTA TAT CAG CCC CAG CAT TTT GGT GAT GGG ACT CGA CTC TCC ATC CT Tyr Leu Arg Ala $\quad$ Ser Ser Leu Thr Gln Arg Val Tyr Gln Pro Gln His Phe Gly Asp Gly Thr Arg Leu Ser Ile BV24J2S7 TAC CTG TGT GCC ACC AGC AGA GCC CTA GAA CAG GGG GCG ATT TTC GGG CCG GGC ACC AGG CTC ACG GTC Tyr Leu Cys Ala Thr Ser Arg Ala Leu Glu Gln Gly Ala Ile Phe Gly Pro Gly Thr Arg Leu Thr Val

Tumor 4

prog. BV14J2S1 TAC TTC TGT GCC AGC AGT TTC GGA CTA GCC CCC TCG TTT GAT GAG CAG TTC TTC GGG CCA GGG ACA ACG GCT CAC $\underline{\text { Tyr }} \underline{\text { Phe }} \underline{\text { Cys Ala }}$ Ser Ser Phe Gly Leu Ala Pro Ser Phe Asp Glu Gln Phe Phe Glu Pro Gly Thr Thr Ala His

Tumor 4

reg. BV1J2S7 TAT TTC TGT GCC AGC AGG GTA GGG GAC AGG GGA GAT ATA AGG TAC TTC GGG CCG GGC ACC AGG CT $\underline{\text { Tyr }} \underline{\text { Phe }} \underline{\text { Cys }} \underline{\text { Ala }}$ Ser Arg Val Gly Asp Arg Gly Asp Ile Arg Tyr Phe Gly Pro Gly $\underline{\text { Thr }}$ Arg

reg, Regressive; prog, progressive. 5'-end V-region and $\mathrm{BJ}$ consensus sequence is underlined. 
Here, we have attempted to answer this question by analyzing progressive and regressive parts of the same primary tumors. Our data clearly indicate that clonal $\mathrm{T}$ cell expansions take place in both regressive and progressive regions of the tumor and that the $\mathrm{T}$ cell responses directed against the progressive and regressive parts are strikingly different. Recent studies have shown major differences in the BV-expression of TILs when primary tumors were compared with metastatic tumors (11). In the present study, we demonstrate that these differences might actually be present in the primary tumor but become apparent only when different parts of the tumor are analyzed separately. In fact, although in some cases the same $\mathrm{BV}$-regions are expressed in both parts of the tumor (i.e., BV13 in tumor 1, BV5 tumor 4) sequence analysis of the CDR3 region showed that they are not derived from the same monoclonal T cell expansion. Several explanations can be put forward to account for these marked discrepancies. The differences in BV-region expression may be the result of different antigens expressed on tumor cells present in regressive versus progressive areas. However, it should be noted that different TCR rearrangements are able to react with the same $\mathrm{MHC} /$ peptide complex (19-22). Nevertheless, Sensi and colleagues (23) reported that the majority of cytotoxic T cell clones recognizing MART-1/Melan-A in the context of HLA-A2 ${ }^{+}$use TCRBV7 or TCRBV14. Recently, this was followed by an analysis of TCRBV in HLA-A $2^{+}$primary tumors showing that TCRBV14 was highly expressed in all tumors examined (4). Taken together, these data indicate that although different TCRs may recognize the same HLA/peptide complex, there is strong selection of receptors carrying certain TCRAV/BV chains. In the present study, 3 out of 4 tumors, two of which were found to be HLA-A2 $2^{+}$(tumors 2 and 4 ) showed expression of TCRBV14. Tumor 4 show expression of BV7 in the regressive part and BV14 in the progressive part. In addition, tumor 2 showed a clonal expansion of TCRBV4 which, similarly to TCRBV14 was capable of recognizing MART-1/Melan-A in the context of HLA-A2. Thus, it is probable that some of the TCRBV-regions found to be expressed in the present study may recognize antigenic peptides derived from the MART-1/Melan-A protein. This conclusion is supported by the fact that practically all melanomas express this protein (4).

It is therefore possible that future studies of TCR usage in HLA typed melanoma lesions may provide further information about the antigens giving rise to the major $\mathrm{T}$ cell responses against melanoma (13).

Although this study is limited to four tumors, the data suggest that $\mathrm{T}$ cell responses may be directed against both regressive and progressive tumor cells. If this is the case, it is likely that HLA or antigen loss are not the major tumor escape mechanism for malignant melanoma. In this regard, it is notable that rather few melanoma cell lines are negative for HLAexpression. We recently analyzed $20 \mathrm{HLA}-\mathrm{A} 2^{+}$melanoma cell lines (FACS ${ }^{\circledR}$ and RT-PCR) and found only one of them to be HLA-A2 negative (20 melanoma cell lines obtained from $\mathrm{HLA}-\mathrm{A} 2^{+}$patients were examined for the expression of HLAA2 allele both by RT-PCR using the primers mentioned in the present paper, and by FACS $^{\circledR}$ analysis using the antibody MA2.1, unpublished observation). Ferrone et al.(17) suggested the loss of expression of genes involved in transport or processing of the antigen for presentation with HLA class I as a tumor escape mechanism. In this context, we have analyzed 25 melanoma cell lines for the expression of transcripts coding for such proteins, i.e., TAP1 and 2 as well as LMP2 and 7. In this rather large material, we could not detect any loss of expression for any of these proteins. (25 melanoma cell lines were examined for the expression of TAP1 and 2 and LMP2 and 7. The analysis was carried out by RT-PCR and specific primers for the mentioned transcripts. All cell lines were shown positive; thor Straten et al., unpublished results.) Therefore this appears to be a highly unlikely mechanism for tumor immune escape in melanoma. Thus, the question why $\mathrm{T}$ cell seemingly capable of rejecting the tumor fail to do so, remains elusive. A recent study analyzed cytokine expression in metastatic melanomas and found no expression of IL-2, IL-4, and INF- $\gamma$, suggesting that the TILs do not transcribe the genes typically induced by antigen activation (24). Furthermore, it has been shown that melanoma cells may render $\mathrm{T}$ cells anergic by initiation of endogenous IL-10 production (25). Similar results were recently shown in a murine model by analyzing rejected (secondary) versus non-rejected (primary) tumors (EMT6) for expression of TCRBV and the cytokines IL-10, TNF- $\alpha$, IFN- $\gamma$, and TGF- $\beta$. The $\mathrm{T}$ cell activating cytokines IFN- $\gamma$ and TNF- $\alpha$ were expressed at lower levels in the progressing tumor whereas the expression of TGF- $\beta$ was significantly higher in the progressing tumor (26). It is therefore possible, that the cytokine balance in the microenvironment plays an important role in determining the outcome of the antitumor immune responses. Future studies of TCRV expression in T cells infiltrating melanomas should therefore incorporate the analysis of cytokine expression both at mRNA and protein level.

\section{Acknowledgments}

We thank Dr. Alexei F. Kirkin for FACS data concerning melanoma cell lines. Jürgen C. Becker is a fellow of the Deutsche Forschungsgemeinschaft.

This work was supported by a grant from the Danish Cancer Society.

\section{References}

1. Cole, W.H. 1976. Spontaneous regression of cancer and the importance of finding its cause. Natl. Cancer Inst. Monogr. 44:5-9.

2. thor Straten, P., J. Schøller, K. Hou Jensen, and J. Zeuthen. 1994. Preferential usage of $\mathrm{T}$ cell receptor alpha beta variable regions among tumor-infiltrating lymphocytes in primary human malignant melanomas. Int. J. Cancer. 56: 78-86.

3. Ferradini, L., S. Roman-Roman, J. Azocar, M.F. Avril, S. Viel, F. Triebel, and T. Hercend. 1992. Analysis of T cell receptor alpha/beta variability in lymphocytes infiltrating a melanoma metastasis. Cancer Res. 52:4649-4654.

4. Salvi, S., F. Segalla, S. Rao, F. Arienti, M. Sartori, G. Bratina, E. Caronni, A. Anichini, C. Clemente, G. Parmiani et al. 1995. Overexpression of the T cell receptor beta-chain variable region TCRBV14 in HLA-A2-matched primary human melanomas. Cancer Res. 55:3374-3379.

5. Clark, W.H. 1991. Tumour progression and the nature of cancer. Br. J. Cancer. 64:631-644.

6. Chomczynski, P., and N. Sacchi. 1987. Single-step method of RNA isolation by acid guanidinium thiocyanate-phenol-chloroform extraction. Anal. Biochem. 162:156-159.

7. Kirkin, A., T.R. Petersen, A.C. Olsen, L. Li, P. thor Straten, and J. Zeuthen. 1995. Generation of human-melanoma specific T lymphocyte clones defining novel cytolytic targets with panels of newly established melanoma cell lines. Cancer Immunol. Immunother. 41:71-81.

8. Zemmour, J., and P. Parham. 1993. HLA Class I nucleotide sequences. 1992. Immunobiology. 187:70-101.

9. Johnston, R.F., S.C. Pickett, and D.L. Barker. 1990. Autoradiography using storage phosphor technology. Electrophoresis. 11:355-360.

10. Cole, W.H. 1976. Relationship of causative factors in spontaneous regression of cancer to immunologic factors possibly effective in cancer. J. Surg. Oncol. 8:391-411.

11. Schøller, J., P. thor Straten, A. Birck, E. Siim, K. Dahlstrøm, K.T. Drzewiecki, and J. Zeuthen. 1994. Analysis of T cell receptor alpha beta variability 
in lymphocytes infiltrating melanoma primary tumours and metastatic lesions. Cancer Immunol Immunother 39:239-248.

12. Mackensen, A., L. Ferradini, G. Carcelain, F. Triebel, F. Faure, S. Viel, and T. Hercend. 1993. Evidence for in situ amplification of cytotoxic T-lymphocytes with antitumor activity in a human regressive melanoma. Cancer Res. 53: 3569-3573.

13. Sensi, M., and G. Parmiani. 1995. Analysis of TCR usage in human tumors:a new tool for assessing tumor-specific immune responses. Immunol. Today. 16:588-595.

14. Kelly, J.W., R.W. Sagebiel, and M.S. Blois. 1985. Regression in malignant melanoma. A histologic feature without independent prognostic significance. Cancer. 56:2287-2291.

15. Weidmann, E., E.M. Elder, M. Trucco, M.T. Lotze, and T.L. Whiteside. 1993. Usage of $\mathrm{T}$ cell receptor $\mathrm{V}$ beta chain genes in fresh and cultured tumorinfiltrating lymphocytes from human melanoma. Int. J. Cancer. 54:383-390.

16. Russo, V., C. Traversari, A. Verrecchia, M. Mottolese, P.G. Natali, and C. Bordignon. 1995. Expression of the MAGE gene family in primary and metastatic human breast cancer: implications for tumor antigen-specific immunotherapy. Int. J. Cancer. 64:216-221.

17. Ferrone, S., and F. M. Marincola. 1995. Loss of HLA class I antigens by melanoma cells:molecular mechanisms, functional significance and clinical relevance. Immunol. Today. 16:487-494.

18. Lehmann, F., M. Marchand, P. Hainaut, P. Pouillart, X. Sastre, H. Ikeda, T. Boon, and P.G. Coulie. 1995. Differences in the antigens recognized by cytolytic $\mathrm{T}$ cells on two successive metastases of a melanoma patient are consistent with immune selection. Eur. J. Immunol. 25:340-347.

19. Nanda, N.K., K.K. Arzoo, H.M. Geysen, A. Sette, and E.E. Sercarz. 1995. Recognition of multiple peptide cores by a single T cell receptor. J. Exp.
Med. 182:531-539.

20. Nanda, N.K., K.K. Arzoo, and E.E. Sercarz. 1992. In a small multideterminant peptide, each determinant is recognized by a different $\mathrm{V}$ beta gene segment. J. Exp. Med. 176:297-302.

21. Cole, D.J., D.P. Weil, P. Shamamian, L. Rivoltini, Y. Kawakami, S. Topalian, C. Jennings, S. Eliyahu, S.A. Rosenberg, and M.I. Nishimura. 1994 Identification of MART-1-specific T cell receptors: $\mathrm{T}$ cells utilizing distinct $\mathrm{T}$ cell receptor variable and joining regions recognize the same tumor epitope. Cancer Res. 54:5265-5268.

22. Romero, P., C. Pannetier, J. Herman, C.V. Jongeneel, J.C. Cerottini, and P.G. Coulie. 1995. Multiple specificities in the repertoire of a melanoma patients cytolytic T lymphocytes directed against tumor antigen MAGE-1.A1. J. Exp. Med. 182:1019-1028.

23. Sensi, M., C. Traversari, M. Radrizzani, S. Salvi, C. Maccalli, R. Mortarini, L. Rivoltini, C. Farina, G. Nicolini, T. Wölfel et al. 1995. Cytotoxic T-lymphocyte clones from different patients display limited $\mathrm{T}$ cell-receptor variable-region gene usage in HLA-A2-restricted recognition of the melanoma antigen Melan-A/MART-1. Proc. Natl. Acad. Sci. USA. 92:5674-5678.

24. Lüscher, U., L. Filgueira, A. Juretic, M. Zuber, N.J. Lüscher, M. Heberer, and G.C. Spagnoli. 1994. The pattern of cytokine gene expression in freshly excised human metastatic melanoma suggests a state of reversible anergy of tumor-infiltrating lymphocytes. Int. J. Cancer. 57:612-619.

25. Becker, J.C., C. Czerny, and E.B. Bröcker. 1994. Maintenance of clonal anergy by endogenously produced IL-10. Int. Immunol. 6:1605-1612.

26. Kurt, R.A., J.A. Park, M.C. Panelli, S.F. Schluter, J.J. Marchalonis, B. Carolus, and E.T. Akporiaye. 1995. T lymphocytes infiltrating sites of tumor rejection and progression display identical $\mathrm{V}$ beta usage but different cytotoxic activities. J. Immunol. 154:3969-3974. 